\title{
Benign Gastric Outlet Obstruction Surgery: A Tertiary
}

\section{Center Experience}

\author{
Ümit Haluk Iliklerden ${ }^{1^{*}}$, Tolga Kalayci ${ }^{2}$, Mehmet Çetin Kotan ${ }^{1}$ \\ ${ }^{1}$ Department of General Surgery, Faculty of Medicine, Van Yuzuncu Yil University, Van \\ ${ }^{2}$ Erzurum Regional Education and Research Hospital General Surgery Clinic, Erzurum, Turkey
}

\begin{abstract}
Introduction
Gastric outlet obstruction (GOO) is a clinical diagnosis that includes abdominal pain, postprandial nausea with or without vomiting, early satiety, and abdominal discomfort. In chronic cases, weight loss can also be added to the symptoms. In this study, it was aimed to examine the characteristics of gastric outlet obstructions underwent surgery for benign reasons in a single tertiary center.

Patients who were operated due to benign gastric outlet obstruction between 2010 and 2018 in the Van Yuzuncu Yil University Departmant of General Surgery were selected retrospectively. Preoperative, intraoperative and postoperative data of the patients were collected from hospital records. The diagnosis process and treatment approaches of the patients were evaluated in the light of the literature.

Average age of 9 patients participating in the study was $47.4 \pm 12.18$ years (26-58) and the male/female ratio was 2 . The most common symptom was abdominal pain $(77.8 \%)$, while the most common symptom was dehydration $(66.7 \%)$. In endoscopy, 8 patients had stenosis and 5 had ulcers. Billroth II gastrectomy was the main surgical procedure performed $(\mathrm{n}=7,77.7 \%)$. Chronic gastritis $(66.7 \%)$ was the main diagnosis in the pathological samples. In addition, Helicobacter pylori positivity was observed in $7(77.8 \%$ ) of 9 patients. Morbidity and mortality rates of the study were $33.3 \%$ and $22.2 \%$, respectively. GOO due to benign diseases is a rare problem. Endoscopic methods and symptomatic treatments should be tried primarily in the treatment of GOO. If there is no improvement in symptoms and signs despite symptomatic treatments, surgical treatment should be applied.
\end{abstract}

Keywords: Abdominal pain, Gastric outlet obstruction, Gastrectomy, Peptic ulcer disease

\section{Introduction}

Gastric outlet obstruction (GOO) is a clinical diagnosis that includes abdominal pain, postprandial nausea with or without vomiting, early satiety, and abdominal discomfort. In chronic cases, weight loss can also be added to the symptoms. (1) GOO etiology can be divided into two main categories: Mechanical obstruction and motility disorders. While GOO caused by mechanical obstruction can be due to many diseases (benign or malignant), GOO resulting from motility disorders is usually caused by gastroparesis. (2) Benign disease comprised the majority of cases of GOO, with common etiologies including peptic ulcer disease, caustic ingestion, pancreatitis, and extraluminal fluid collections. (3) The most common cause of benign cases is peptic ulcer disease, occurring in about $90 \%$ of cases. (4)

Benign GOO presents a unique challenge for patients and clinicians. Surgical bypass is a permanent, anatomy-altering procedure with associated both morbidity and mortality. (3) Although alternative approaches, such as endoscopic balloon dilatation, steroid injection or stents, to surgery are applied due to morbidity and mortality, surgery is inevitable in some cases.

In the presented study, the diagnosis process and treatment approaches of the patients who were operated because of benign gastric outlet obstruction were evaluated in the light of the literature.

\section{Material and Methods}

Patients who were operated due to benign gastric outlet obstruction between 2010 and 2018 Van Yuzuncu Yil University Departmant of General Surgery were selected retrospectively. Hospital records, operation notes, pathology reports and clinical charts of the patients were evaluated.

\footnotetext{
${ }^{*}$ Corresponding Author: Ümit Haluk İliklerden, Van Yuzuncu Yil University Faculty of Medicine, Department of General Surgery, 65080, Van, Turkey

E-mail: umithalukiliklerden@hotmail.com, Telephone: +900 (532) 6579933

ORCID ID: Ümit Haluk Iliklerden: 0000-0003-3950-5535, Tolga Kalayci: 0000-0002-6977-1757, Mehmet Çetin Kotan: 0000-0002-6336- 


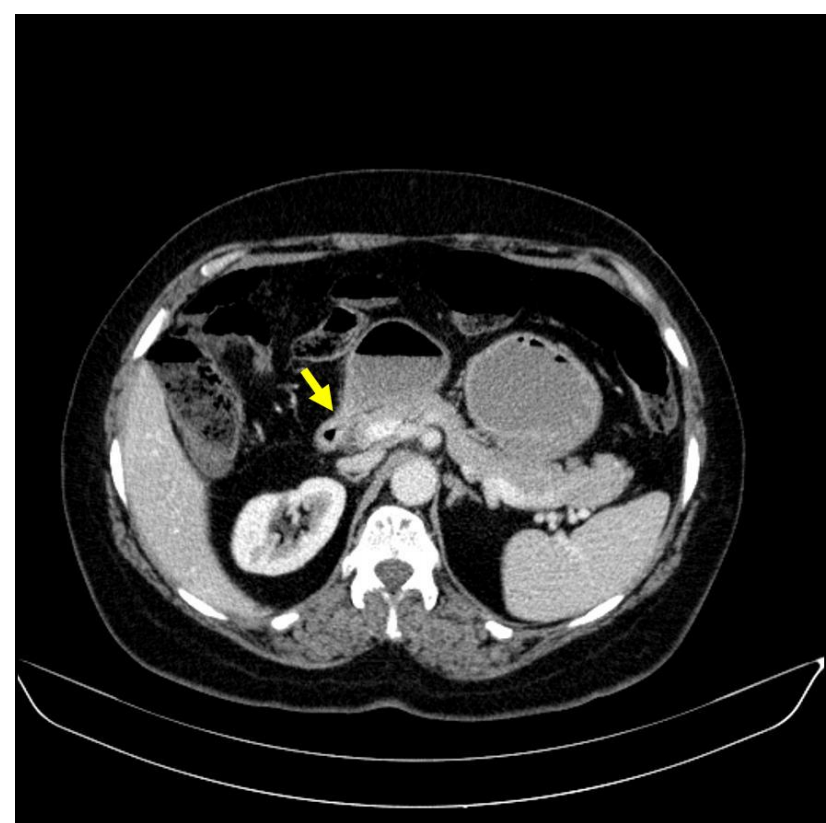

Fig. 1. A case of gastric outlet obstruction in a 53year-old male patient who presented to the emergency department with abdominal pain and vomiting. Axial CT image shows pyloric thickening (yellow arrow)

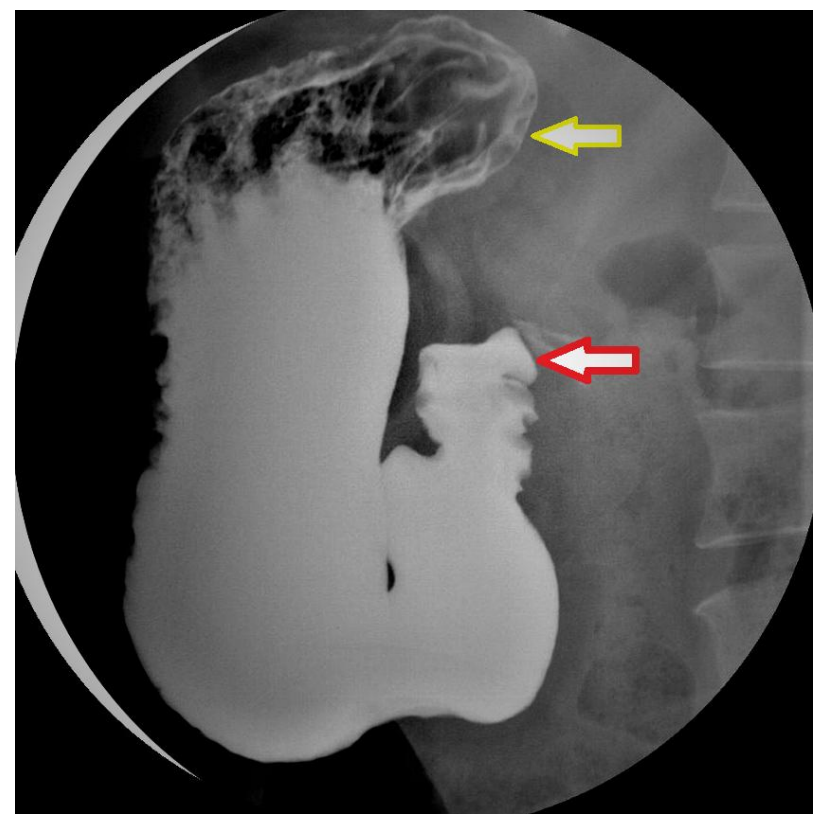

Fig. 2. Esophagogastroduodenoscopy image of the patient whose tomography was given in Figure 1. The image shows that there is no contrast transition to the duodenum (red arrow). And an enlarged stomach and swollen fundic air (yellow arrow) are seen

Preoperative, intraoperative and postoperative data of the patients were collected. The diagnosis process and treatment approaches of the patients were evaluated in the light of the literature. Age and gender distribution, American Society of Anesthesiologists Classification (ASA) scores, comorbid diseases and preoperative endoscopy reports were analyzed as preoperative factors. Symptoms and signs at admission, laboratory

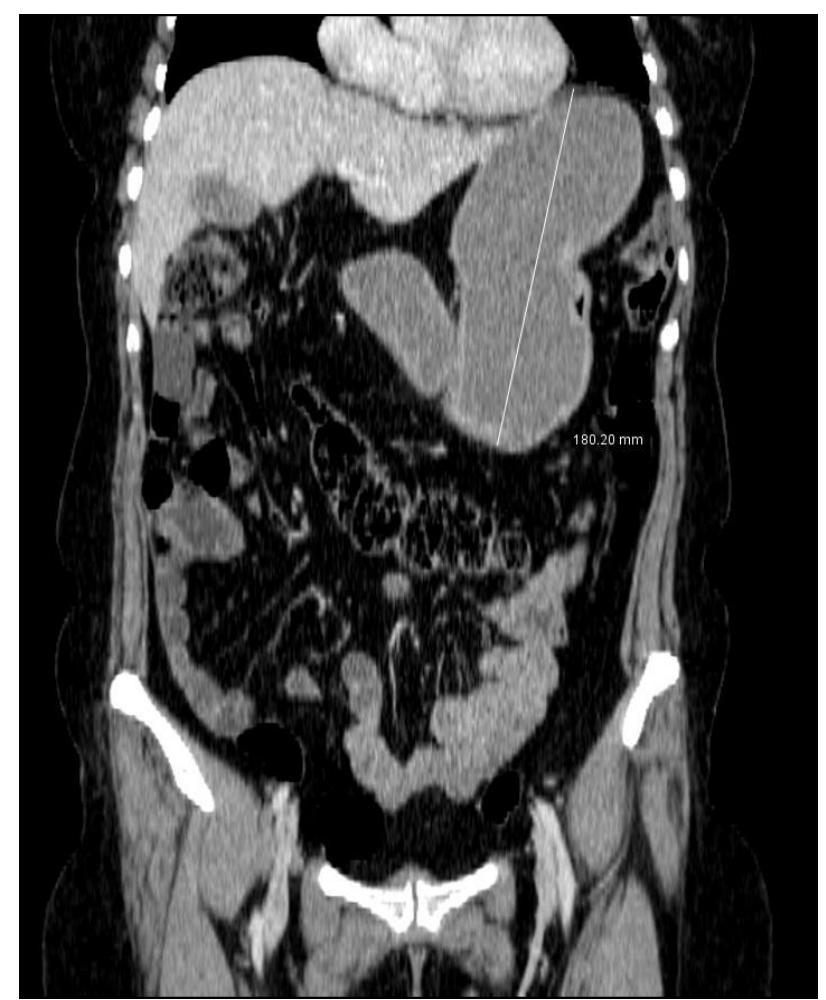

Fig. 3. CT image shows increased gastric cranio-caudal length

findings and diagnostic imaging tools were also evaluated.

Type of abdominal incision, type of surgery, additional organ resection, intraoperative complications and the number of drains placed in the abdominal cavity were checked as intraoperative parameters.

In the pathology reports, the main pathological diagnosis of the resection material, the presence of Helicobacter pylori and lymph node were evaluated postoperatively. Postoperative complications, hospital stay, morbidity and mortality rate were also checked for the study.

Endoscopy was performed on all patients before hospitalization. None of the patients were not suitable for endoscopic balloon dilatation or endoscopic stenting. So, All patients were hospitalized for further evaluation and follow-up.

First, conservative and supportive treatment was applied to all patients for 3 days. $35 \mathrm{ml} / \mathrm{kg}$ daily intravenous (IV) fluid replacement was initiated in the patients. In addition, appropriate replacement therapy was initiated for patients with electrolyte disorders. Omeprazole IV infusion was given to the patients as $40 \mathrm{mg} /$ day intravenous infusion. Nasogastric tube was used for decompression in all patients. However, all cases underwent surgery because the patients did not respond to conservative and supportive treatment. 


\section{Results}

The cases who underwent benign GOO surgery between 2010 and 2018 in the Van Yuzuncu Yil University Departmant of General Surgery were analyzed in a retrospective view. After analysis of the hospital records, there were 9 patients eligible for the study. While the mean age of the patients in the study was 47.4 years (range 26 to 58 years), the male/female ratio $(6 / 3)$ was 2 . The most common ASA score was ASA $2(n=5,55.6 \%)$. The most common symptom was abdominal pain $(77.8 \%)$, while the most common symptom was dehydration $(66.7 \%)$. Endoscopy was performed in all patients before hospitalization. In endoscopy, 8 patients had stenosis and 5 had ulcers. Endoscopy findings are shown in Table 1.

6 patients $(66.7 \%)$ had electrolyte imbalance. The most common electrolyte disorders were hyponatremia $(44.4 \%)$ and hypochloremia $(33.3 \%)$. All electrolyte disorders were fixed before surgery. Endoscopy was used for initial diagnosis. In 8 of 9 patients, abdominal contrastenhanced computed tomography (CT) was used for differential diagnosis (Figure 1). Esophagogastroduodenoscopy was performed in addition to endoscopy in one patient (Figure 2). On the other hand, CT scan was used to evaluate gastric volume before surgery (Figure 3).

All patients operated with open surgery because the patients did not respond to conservative and supportive treatment. Upper Midline Incision (UMI) was the most common used incision in surgery with $66.7 \%$. While Billroth II gastrectomy was the main surgical procedure $(n=7,77.7 \%)$, Billroth I gastrectomy and Whipple procedures were the other procedures. Cholecystectomy was performed in 2 patients additionally. In addition, one patient had concomitant pneumatosis intestinalis. No surgical resection was applied to this patient. There were no intraoperative complications in any of the patients. The drain (s) used during the surgery were placed in the preanastomotic areas and pelvic cavity. While at least 1 drain was used in all patients, 2 or 3 drains were placed in some cases depending on the extensiveness of the surgery performed. Preoperative and intraoperative data of the patients are given in Table 1. Chronic gastritis $(66.7 \%)$ was the main diagnosis in pathological resection material. Reactive lymph nodes were seen in the pathology samples of 4 patients (mean: 8.75 lymph nodes [range: 4-12]). Helicobacter pylori positivity was observed in $7(77.8 \%)$ of 9 patients in the pathological samples.
The overall length of stay (LOS) ranged from 5 to 52 days with a median of 13.8 days. Morbidity and mortality rates of the study were $33.3 \%(\mathrm{n}=3)$ and $22.2 \%(\mathrm{n}=2)$, respectively. Postoperative ileus was seen in one patient. The patient with ileus was treated with nasogastric decompression and laxative therapy. The patient with ileus also had a surgical site infection and was treated with daily cleaning and antibiotherapy. Anastomotic leakage was observed in one patient and the patient underwent surgery again because of the high-flow enterocutaneous fistula. Doudenum stump revision with Hepaticojejunostomy and TTube drainage was applied to the patient (Table 2). Despite revisional surgery, the patient died on the $52^{\text {nd }}$ postoperative day because of sepsis. Hospital-acquired pneumoniae occurred in one patient, and the patient died because of disseminated intravascular coagulation on the $8^{\text {th }}$ postoperative day.

\section{Discussion}

Gastric outlet obstruction (GOO) is a rare entity that is localized antro-pyloric area or duodenum. (5) Many diseases (benign or malignant) play a role in the etiology of GOO. The most common cause is peptic ulcer disease that occurs approximately $90 \%$ of benign cases. Due to successful treatment of Helicobacter pylori, the incidence of GOO from peptic ulcer disease has descreased to about $5 \%$ nowadays. Obstructive complications occur in less than $5 \%$ of complicated duodenal ulcer disease and less than 1-2\% of complicated gastric ulcer disease. (4)

In literature studies, the most common cause of benign GOO detected preoperatively was peptic ulcer disease. While the rates of peptic ulcer disease were as follows: $46 \% 6,41.5 \% 7$, and $63.4 \% 8$ in literature, in our study this rate was $88.9 \%$ and it was higher than literature. The mean age was 47.52 years (range from 22 to 73 years) in the study of Kumar et al. (6), which included benign and malignant cases, while the mean age was 34 in the study by Jaka et al. which included only benign cases. (8) Majority of patients were in the age group of $<40$ years $(34.1 \%)$, followed by $41-50$ years $(24.4 \%)$ in the study of Ellis et al. (9) In the series of Fisher et al. (10) the average age was 54 with a span from 20 to 89 years and men outnumbered women by 2:1. Our study's mean age was 47.4 years and male to female ratio was 2 . Both Jaka et al's study (8) and our study, the majority of patients had ASA class II score (Jaka et al.: $33.4 \%$, our study: $55.6 \%$ ). 
Iliklerden et al / Benign Gastric Outlet Obstruction Surgery

Table 1. Clinical Evaluation of Patients Underwent Goo Surgery For Benign Pathologies

\begin{tabular}{|c|c|c|c|c|c|c|c|c|}
\hline $\begin{array}{l}\text { Case } \\
\text { Number }\end{array}$ & Gender & $\begin{array}{l}\text { Mean } \\
\text { Age } \\
\text { (year) }\end{array}$ & $\begin{array}{l}\text { History of } \\
\text { Patients }\end{array}$ & $\begin{array}{l}\text { ASA } \\
\text { score }\end{array}$ & Symptoms & Signs & Endoscopical Findings & Laboratory Changes \\
\hline 1 & Male & 53 & No & 2 & $\mathrm{AP}+\mathrm{N} \& \mathrm{~V}$ & $\mathrm{D}$ & $\begin{array}{c}\text { Stenosis in pyloric area } \\
\text { and ulcer }\end{array}$ & $\begin{array}{c}\text { Hyponatremiat Increased } \\
\text { creatinine level }\end{array}$ \\
\hline 2 & Male & 49 & No & 1 & $\begin{array}{c}\text { AP }+ \text { Postprandial } \\
\text { Fullness }\end{array}$ & Pallor & $\begin{array}{l}\text { Stenosis in duodenal } \\
\text { bulbus }\end{array}$ & No \\
\hline 3 & Female & 26 & No & 2 & $\begin{array}{c}\mathrm{N} \& \mathrm{~V}+\mathrm{W} \text { eight } \\
\text { Loss }\end{array}$ & $\mathrm{D}$ & $\begin{array}{l}\text { Stenosis in duodenal } \\
\text { bulbus and ulcer }\end{array}$ & Hypercholoremia \\
\hline 4 & Male & 58 & No & 1 & $\mathrm{AP}+\mathrm{N} \& \mathrm{~V}$ & $\mathrm{D}$ & $\begin{array}{c}\text { Stenosis in pyloric area } \\
\text { and ulcer }\end{array}$ & $\begin{array}{c}\text { Hypercholoremia }+ \\
\text { Increased amilase Level }\end{array}$ \\
\hline 5 & Male & 56 & $\begin{array}{l}\text { Cigarette, } \\
\text { Testicular } \\
\text { Cancer, } \\
\text { Radiotherapy }\end{array}$ & 2 & $\begin{array}{l}\text { AP }+ \text { Vomiting }+ \\
\text { Weight Loss }\end{array}$ & $\mathrm{D}$ & $\begin{array}{c}\text { Stenosis in pyloric area } \\
\text { and ulcer }\end{array}$ & No \\
\hline 6 & Female & 31 & No & 1 & $\begin{array}{l}\mathrm{N} \& \mathrm{~V}+ \\
\text { Postprandial } \\
\text { Fullness }\end{array}$ & $\begin{array}{c}\text { Splash } \\
+ \\
\text { Palpable } \\
\text { Mass }\end{array}$ & $\begin{array}{l}\text { Stenosis in pre-pyloric } \\
\text { area and pitotic gaster }\end{array}$ & $\begin{array}{c}\text { Hyponatremia }+ \\
\text { Hypopotasemia }+ \\
\text { Increased creatinine level }\end{array}$ \\
\hline 7 & Male & 56 & No & 2 & $\begin{array}{l}\mathrm{AP}+\text { Vomiting }+ \\
\text { Weight Loss }\end{array}$ & $\mathrm{D}$ & $\begin{array}{l}\text { Nodular mucosal } \\
\text { structures }\end{array}$ & $\begin{array}{c}\text { Hyponatremia }+ \\
\text { Hypopotasemia }+ \\
\text { Hypocholoremia }\end{array}$ \\
\hline 8 & Male & 40 & No & 1 & $\mathrm{AP}+$ Constipation & Pallor & $\begin{array}{c}\text { Stenosis in pre-pyloric } \\
\text { area }\end{array}$ & Hyponatremia \\
\hline 9 & Female & 58 & HT & 2 & $\begin{array}{l}\text { AP }+ \text { Vomiting }+ \\
\text { Weight Loss }\end{array}$ & $\begin{array}{c}\mathrm{D}+ \\
\text { Splash } \\
+ \\
\text { Palpable } \\
\text { mass }\end{array}$ & $\begin{array}{l}\text { Stenosis in duodenal } \\
\text { bulbus and ulcer }\end{array}$ & No \\
\hline
\end{tabular}

East J Med Volume:26, Number:3, July-September/2021 
Table 2. Intraoperative and Postoperative Data of The Patients

\begin{tabular}{|c|c|c|c|c|c|c|c|c|c|}
\hline $\begin{array}{l}\text { Case } \\
\text { Number }\end{array}$ & $\begin{array}{l}\text { Incision } \\
\text { Type }\end{array}$ & $\begin{array}{l}\text { Surgery } \\
\text { Type }\end{array}$ & $\begin{array}{l}\text { Additional } \\
\text { Resection }\end{array}$ & Pathology & $\begin{array}{l}\text { Reactive } \\
\text { Lymph } \\
\text { Node }\end{array}$ & HP & $\begin{array}{l}\text { Postoperative } \\
\text { Complication }\end{array}$ & $\begin{array}{c}\text { Hospital Stay } \\
\text { (day) }\end{array}$ & Mortality \\
\hline 1 & UMI & Billroth II & No & $\begin{array}{l}\text { Ulceration with Brunner } \\
\text { gland hyperplasia }\end{array}$ & 4 & +1 & No & 6 & No \\
\hline 2 & UMI & Billroth II & No & $\begin{array}{l}\text { Fibrosis with Active } \\
\text { inflammation }\end{array}$ & 12 & $+2 /+3$ & No & 14 & No \\
\hline 3 & UMI & Billroth I & No & Chronic gastritis & 0 & +1 & No & 8 & No \\
\hline 4 & UMI+LMI & Billroth II & Cholecystectomy & $\begin{array}{l}\text { Inflammatuar } \\
\text { pseudotumor }\end{array}$ & 10 & +1 & Pneumoniae & 8 (DIC) & Yes \\
\hline 5 & $\begin{array}{c}\text { DL+ } \\
\mathrm{UMI}+\mathrm{LMI}\end{array}$ & Billroth II & No & $\begin{array}{c}\text { Chronic gastritis with } \\
\text { ulceration }\end{array}$ & 9 & +3 & No & 8 & No \\
\hline 6 & UMI & Billroth II & No & Chronic gastritis & 0 & No & $\begin{array}{c}\text { Anastomotic } \\
\text { leakage }\end{array}$ & 52 (Sepsis) & Yes \\
\hline 7 & UMI & Billroth II & $\begin{array}{c}\text { Pneumatosis } \\
\text { intestinalis }\end{array}$ & Chronic gastritis & 0 & +1 & No & 9 & No \\
\hline 8 & $\mathrm{UMI}+\mathrm{LMI}$ & $\begin{array}{l}\text { Whipple } \\
\text { procedure }\end{array}$ & No & $\begin{array}{l}\text { Chronic gastritis with } \\
\text { pyloric hypertrophy }\end{array}$ & 0 & No & Ileus + SSI & 15 & No \\
\hline 9 & UMI+LMI & Billroth II & Cholecystectomy & $\begin{array}{l}\text { Chronic gastritis with } \\
\text { pyloric hypertrophy }\end{array}$ & 0 & +2 & No & 5 & No \\
\hline
\end{tabular}


Symptoms in GOO depend on the underlying disease. While the most common symptoms were abdominal or epigastric pain, and vomiting, the most common signs were splash and dehydration in studies. $(6,8)$ Also, approximately $25 \%$ of the patients have abdominal distension, which indicates a blocked gastric outlet. In some patients, vomiting of the waited gastric contents also suggests GOO. (5) However, in chronic cases or malignant cases weight loss, malnutrition, and chronic pain can be the main symptoms. (11) Thus, the main diagnosis can be put by questioning the symptoms. The most common symptom was abdominal pain $(77.8 \%)$, while the most common symptom was dehydration $(66.7 \%)$ in our study similar to the literature.

In laboratory, metabolic alkalosis with hypochloremia and hypopotasemia are often present after severe vomiting. On the other hand, it can be seen that gastrin levels increase due to abdominal distension. While in the study of Weiland et al. (12) electrolyte disorder was present $30 \%$, in the other study of Nataraj et al. (7) electrolyte disorder was present $70.7 \%$. In our study, 6 of 9 patients $(66.7 \%)$ had electrolyte imbalance.

Swollen fundic air that does not cross the midline can be seen on plain radiography. Studies with barium or water-soluble contrast can provide information about the underlying cause. If there is no contrast transition to the small intestine, a complete obstruction should be considered. CT scan can provide additional information such as thickness of pylorus and gastric wall, and also reveal whether lymph nodes or pancreatic lesions are present.

GOO treatment due to benign reasons should be done depending on the underlying cause. Treatment of GOO for benign diseases can be divided into two main groups: nonsurgical treatment and surgical treatment. Non-surgical treatments include conservative and supportive treatment, Endoscopic Balloon Dilation (EBD), intralesional steroids, endoscopic incision, SelfExpanding Metal Stent (SEMS), and endoscopic ultrasound-guided gastroenterostomy using Lumen-Appropriate Metal Stent (LAMS). Surgical treatments include resective surgeries and nonresective (divertive) surgeries.

Patients with symptomatic GOO should be followed in hospital. Fluid resuscitation and replacement of electrolyte imbalance should be performed first. Nasogastric tube (NT) should be used for decompression. NT helps to relieve discomfort and pain caused by stomach fullness, cleanse the area before the endoscopic procedure, and reduce stomach capacity prior to surgery. On the other hand, acid suppression with proton pump inhibitors, discontinuation of nonsteroidal anti-inflammatory drugs, and Helicobacter pylori eradication were the other methods. In peptic ulcer disease, conservative and supportive treatment help to settle oedema and solve the main problem. (13-15)

In cases not responding to conservative and supportive treatment, Endoscopic Balloon Dilation (EBD) may be attempted. Benjamin et al. (15) first reported the use of EBD for the treatment of GOO. EBD may be an alternative to surgery, with success rates of $76 \%$.(13) However, a study showed that the need for 2 or more dilations was associated with a higher probability of surgery. (16)

Surgery is indicated in cases of GOO in which there is significant obstruction in endoscopy and in cases where medical therapy and endoscopic treatments have failed. In the study of Weiland et al., 49 of 87 patients underwent surgery when the obstruction did not resolve despite medical treatment. (12) The most common performed surgery was gastrojejunostomy $61.9 \%$ to $100 \%$ in all series. $(6-8,10,17)$ Also, in our series, rate of gastrojejunostomy was $100 \%(77.8 \%$ Billroth II gastrectomy, $11.1 \%$ Billroth I gastrectomy, and $11.1 \%$ Whipple procedure).

Surgical treatment of GOO due to peptic strictures includes surgical resection of the pathological segment or pyloroplasty. Vagotomy can be added to surgery depending on the etiology. Gastrojejunostomy may be considered in patients with preserved anatomy. On the other hand, Roux-en-Y jejunostomy should be preferred if the anatomy has been changed. These surgical techniques can be performed with open surgery or laparoscopic surgery. (18) Laparoscopic surgery may be gold standard in the future because of positive effects on patients such as lower hospital stay and rapid recovery. (19)

Helicobacter pylori positivity rate detected in pathology samples ranged between $47 \%$ and $91 \% 7,20$, while this rate was found to be $77.8 \%$ in our study. The most common postoperative complication in studies was surgical site infection with an incidence between $14.1 \%$ and $19.5 \%$ (6-8, $10,17)$, and surgical site infection developed at a lower rate $(11.1 \%, n=1)$ than in the literature in this study.

As in the presented study (13.8 days), average length of hospital stay in the literature ranged 
from 10 days to 15 days. $(6-8,10,17)$ The mortality rate in literature studies ranged from $0 \%$ to $18.5 \%$, and the mortality rate in this study was found to be $22.2 \%$, higher than the literature.

In conclusion, GOO due to benign diseases is a rare but serious problem. The incidence of GOO due to peptic ulcer disease is decreasing day by day due to successful treatment of Helicobacter pylori. Therefore such aggressive cases will be less common in the future. Endoscopy is the primary technique for diagnose. GOO should be considered in cases with significant obstruction in the distal stomach or duodenum. Endoscopic treatment methods should be tried first in appropriate cases. In cases where endoscopic treatments fail, symptomatic cases should be followed up in the hospital. In hospital follow-up, conservative and supportive therapy for a few days should be tried first. If there is no improvement in signs and symptoms despite conservative and supportive treatments, appropriate surgical treatment should be applied.

\section{References}

1. Tringali A, Giannetti A, Adler DG. Endoscopic management of gastric outlet obstruction disease. Annals of gastroenterology 2019; 32: 330.

2. Appasani S, Kochhar S, Nagi B, Gupta V, Kochhar R. Benign gastric outlet obstructionspectrum and management. Tropical Gastroenterology 2012; 32: 259-266.

3. James TW, Greenberg S, Grimm IS, Baron TH. EUS-guided gastroenteric anastomosis as a bridge to definitive treatment in benign gastric outlet obstruction. Gastrointestinal endoscopy 2020; 91: 537-542.

4. Kochhar R, Kochhar S. Endoscopic balloon dilation for benign gastric outlet obstruction in adults. World journal of gastrointestinal endoscopy 2010; 2: 29.

5. Khullar SK, DiSario JA. Gastric outlet obstruction. Gastrointestinal endoscopy clinics of North America 1996; 6: 585-603.

6. Kumar H, Naik D, Vasudevaiah T. Gastric outlet obstruction, a clinical study in tertiary care hospital South India. International Journal of Surgery 2019; 3: 198-203.

7. Nataraj NR, Shivaswamy B. Gastric outlet obstruction: an overview clinical presentation and its surgical management in a tertiary care government hospital. Journal of Evolution of Medical and Dental Sciences 2014; 3: 1297112978.
8. Jaka H, Mchembe MD, Rambau PF, Chalya PL. Gastric outlet obstruction at Bugando Medical Centre in Northwestern Tanzania: a prospective review of 184 cases. BMC surgery 2013; 13: 1-8.

9. Nyhus LM. Surgery of the stomach and duodenum: Brown; 1962.

10. Fisher RD, Ebert PA, Zuidema GD. Obstructing peptic ulcers: Results of treatment. Archives of Surgery 1967; 94: 724-727.

11. Ferzoco SJ, Soybel D. Gastric outlet obstruction, perforation and other complications of gastroduodenal ulcer. Therapy of digestive disorders: Elsevier Inc 2006; 357-372.

12. Weiland D, Dunn DH, Humphrey EW, Schwartz ML. Gastric outlet obstruction in peptic ulcer disease: an indication for surgery. The American Journal of Surgery 1982; 143: 90-93.

13. Lam Y-h, Lau JY-w, Fung TM-k, et al. Endoscopic balloon dilation for benign gastric outlet obstruction with or without Helicobacter pylori infection. Gastrointestinal endoscopy 2004; 60: 229-233.

14. Cherian PT, Cherian S, Singh P. Long-term follow-up of patients with gastric outlet obstruction related to peptic ulcer disease treated with endoscopic balloon dilatation and drug therapy. Gastrointestinal endoscopy 2007; 66: 491-497.

15. Benjamin SB, Cattau EL, Glass RL. Balloon dilation of the pylorus: therapy for gastric outlet obstruction. Gastrointestinal Endoscopy 1982; 28 : 253-254.

16. Noor MT, Dixit P, Kochhar R, et al. NSAIDsrelated pyloroduodenal obstruction and its endoscopic management. Diagnostic and therapeutic endoscopy 2011; 2011.

17. Tejas A, Jade R, Srinivas S. Gastric outlet obstruction: clinical presentations and its surgical management. International Surgery Journal 2018; 5: 622-625.

18. Jaffin BW, Kaye MD. The prognosis of gastric outlet obstruction. Annals of surgery 1985; 201 : 176.

19. Al-Rashedy M, Dadibhai M, Shareif A, et al. Laparoscopic gastric bypass for gastric outlet obstruction is associated with smoother, faster recovery and shorter hospital stay compared with open surgery. Journal of hepato-biliary-pancreatic surgery 2005; 12: 474-478.

20. Kate V, Ananthakrishnan N, Tovey FI. Is Helicobacter pylori infection the primary cause of duodenal ulceration or a secondary factor? A review of the evidence. Gastroenterology research and practice 2013; 2013. 